\title{
An automatic system for controlling snow on roofs
}

\author{
MORIAKI TAMURA \\ Nagaoka Technical High School, Saiwaicho 2-7-70, Nagaoka, Niigata 940, Japan
}

\begin{abstract}
In Honshu Island, Japan, tremendous amounts of snow falls over a vast area facing the Sea of Japan. The depth of deposited snow sometimes exceeds $2 \mathrm{~m}$, even in urban areas. The weight of snow on roofs can damage conventional wooden houses. It is of great importance, therefore, to monitor and control roof snow loads.

A model system has been developed for controlling snow on roofs. A precipitation detector capable of differentiating between solid and liquid precipitation and a water gauge for detecting the meltwater from a roof are combined to estimate the roof snow load. When the calculated load exceeds a critical value, an electric heater on the roof is energized to melt a portion of the snow. The whole system is controlled by a personal computer. The system was tested for about a month in 1990 with satisfactory results.
\end{abstract}

\section{INTRODUGTION}

The Hokuriku District of Honshu Island, Japan, faces the Sea of Japan. It is a region of very heavy snowfall where several million people live. In this region the snow cover on the ground may exceed $2 \mathrm{~m}$.

On a global scale, the average winter temperature of this area is not very low as it remains around $0^{\circ} \mathrm{C}$. Water vapor over the Sea of Japan is driven to Japan by the seasonal wind from the continent, often causing the relative humidity to exceed $80 \%$. Dwelling houses, which are traditionally built of wood, are not strong enough to sustain full snow loads: deep snow sometimes blocks doors, deforms structures, or causes collapse of the whole house. In order to prevent such disasters, the residents periodically climb onto their roofs to remove snow with shovels, scoops and so forth before the snow load reaches the limit of $4000 \mathrm{Nm}^{-2}$. This form of snow removal is highly dangerous, and every year results in casualties. In order to eliminate those tragedies a number of devices to melt snow on the roof have been developed.

There are several methods used to dispose of roof snow by melting. Snow can be melted instantly by spraying warm underground water on the roof, by leading warm air into the attic space, or by installing electric heaters or hot water coils under the roofing. Application of such methods is gradually spreading, however, such devices are expensive to purchase and operate. Since they remove more snow than necessary, their thermal efficiency has not reached satisfactory levels, and automatic controls are primitive. More work is necessary in order to gain practical and efficient control of snow load by melting.

The purpose of this study was to melt snow on roofs more efficiently by keeping the roof snow load below a maximum value while allowing snow to remain on the roof. Another objective was to achieve unattended operation of the apparatus by use of automatic controls and a computer.

\section{METHOD OF MELTING SNOW ON ROOF}

The "Partial Melting Method" was developed by Tadashi Kimura (1974). In this method of melting snow with heaters below the roof, the heaters are energized only when roof snow load exceeds a specified value, for example $3000 \mathrm{Nm}^{-2}$, and only a portion of snow is removed. In so doing, the quantity of heat dissipated into the atmosphere is reduced and thermal efficiency is improved.

In order to use this method, the snow load on the roof must be monitored. Unfortunately, instruments capable of accurately measuring roof snow loads on common dwelling houses are not available. However, by measuring precipitation (snow, rain, hail and sleet) reaching a roof as it falls and the quantity of water that has flowed off the roof, the roof snow load can be calculated.

In this study a method of melting portions of snow on a roof and determining roof snow load by the principle mentioned above is explained.

\section{SYSTEM}

The experimental system is composed of a small model roof with a heater, a precipitation detector, a water tank with a pump, and a personal computer (Fig. 1). The $1.04 \mathrm{~m}^{2}$ roof is horizontal. Its surface is a painted steel plate with a $195 \mathrm{~W}$ electric heater of the film type installed underneath. Below that is a layer of insulation $20 \mathrm{~mm}$ thick. The experimental roof, which is placed on the roof of Nagaoka Technical High School, is shown in Figure 2. 
Tamura: Automatic system for controlling snow on roofs

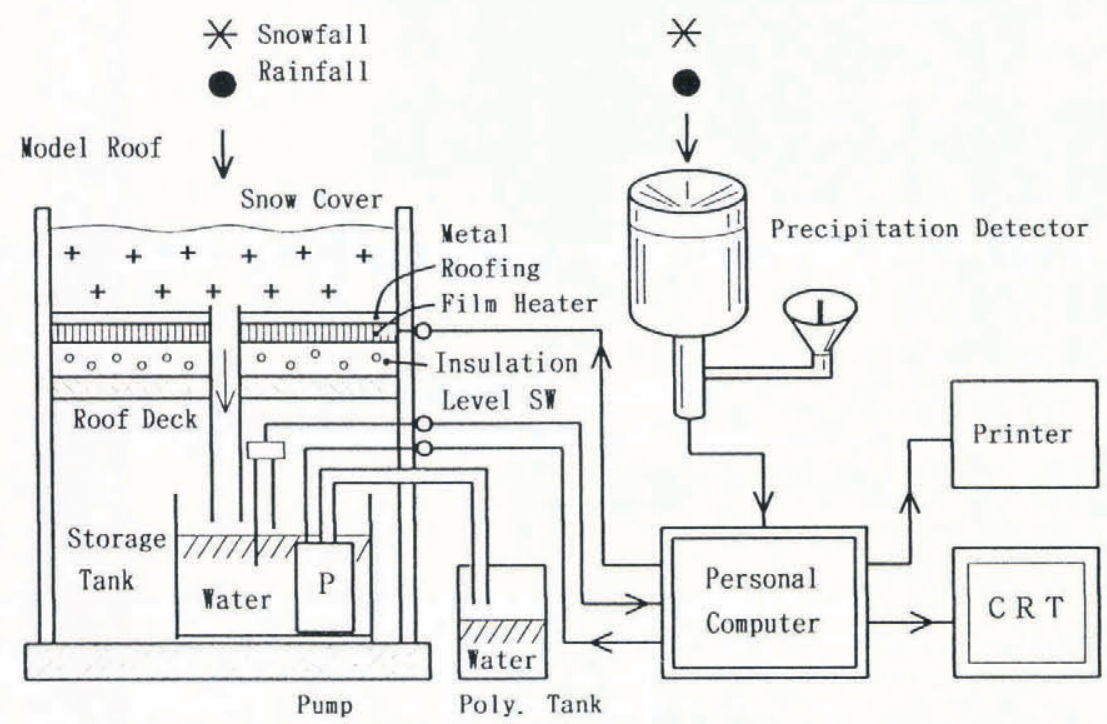

Fig. 1. Block diagram of the experimental set-up.

Water from melted snow on the roof flows down through the drain hole to the water storage tank below the roof. Water in the storage tank is automatically discharged by the submerged pump in known quantities of $0.90 \mathrm{~kg}$ into a secondary tank made of polyvinyl chloride, where its volume is measured manually as a check.

A precipitation detector is located close to the roof. This detector works by counting water drops, and has been developed, for general use, to be compact, lightweight and simple. It consists of water-drop and snowtemperature detecting parts, the structures of which are shown in Figure 3. The detector was described by Tamura (in press). A receptacle in the water-drop detecting part has an aperture cross-sectional area of $117 \mathrm{~cm}^{2}$, and is funnel-shaped to catch raindrops and snowflakes. Caught snowflakes are melted with the $10 \mathrm{~W}$ heater attached to the receptacle.

At the tip of the nozzle of the water duct the water is transformed to water drops, which are precipitated. The drops cross the light beam to be counted one-by-one by a counting device. The smallest measuring unit is $7.0 \mu \mathrm{m}$ for the precipitation, which equals the mass of one water drop divided by the cross-sectional area of the receptacle.

A qualitative discrimination between snowfall (containing sleet and hail) or rain can be performed with a device detecting snow temperature (Fig. 3). The structure

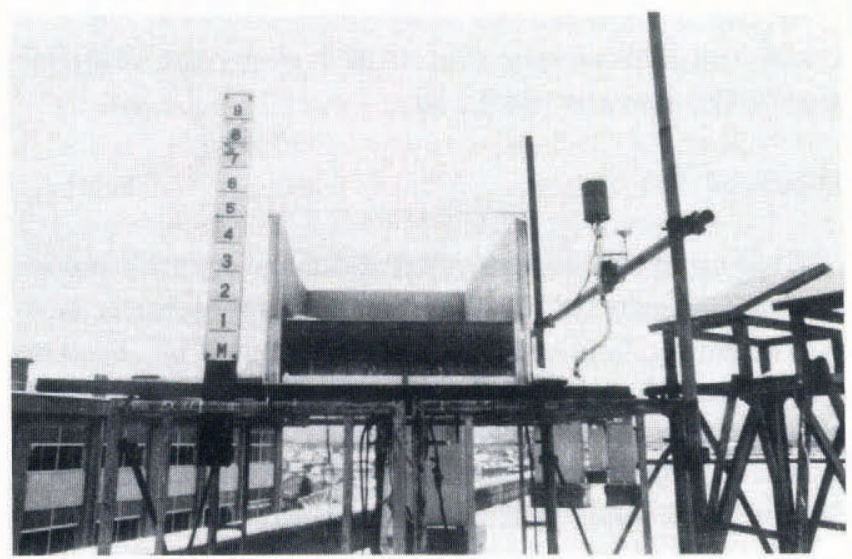

Fig. 2. The experimental roof. consists of a thermistor in the central part of a cup-shaped snow receptacle. When the element temperature is less than the discrimination temperature, the precipitation is recognized as snowfall. When the element temperature is

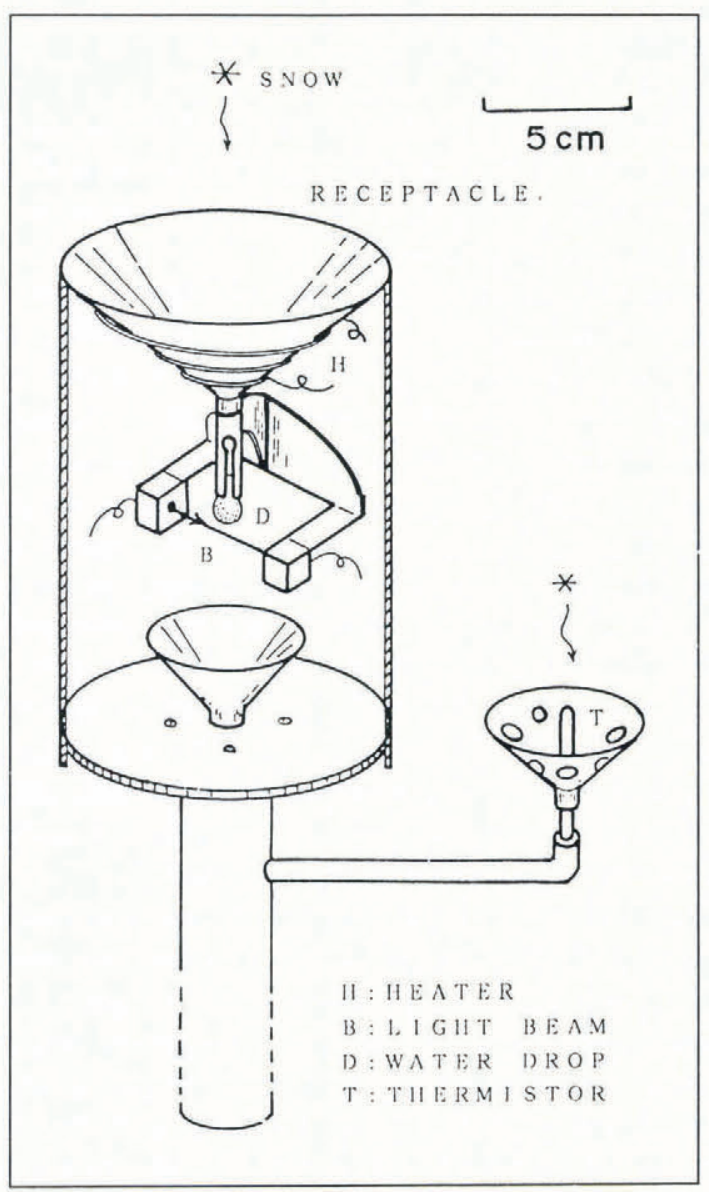

Fig. 3. The precipitation detector.

greater than the discrimination temperature, all precipitation is identified as rain. The discrimination temperature could be set to be $0.7^{\circ} \mathrm{C}$ as described in Tamura (1990). This detector then distinguishes between rain and snow, and measures the weight of snowfall and rainfall 
each minute. The weight of snow and rain is estimated by multiplying a fixed coefficient to the precipitation measured by this detector. This coefficient is determined experimentally and is an indication of the difference between the precipitation measured by the detector and the true precipitation, as described later.

The personal computer records the amount of snowfall and rainfall together with the quantity of water discharged from the roof every minute, then calculates the roof snow load. The values measured and the status of the electric heater are indicated on the CRT every minute. Every day at 0900 the daily total of the measured values, the snow load on the roof as of the day, and the cumulative quantity of water discharged up to the previous day are printed. The computer makes all calculations and uses those answers to determine when the electric heater should be turned on and off.

\section{METHOD OF AUTOMATIG CONTROL}

The experiment functions as follows: First, prior to starting the operation, the upper limit value, $L H$, and the lower limit value, $L L$, are set. $L H$ is the value up to which the snow load is allowed: when the load exceeds this value, action for melting snow is started. $L L$ is the level at which melting action is stopped.

Once the system begins to work, the snowfall detector measures the amount of precipitation, $P \mathrm{kgm}^{-2}$ every minute, distinguishing between snow and rain: these measured values are read and stored by the computer. The product of a coefficient, $k$, and $P$ is estimated to be the precipitation on the roof. $k$ is determined according to difference of precipitation capture between the roof and the detector (for more details see Tamura, 1990).

The quantity of the water that flows down from the roof to the storage tank is measured to calculate the roof load. The integrated quantity of water discharged, $V$, is subtracted from the integrated precipitation, $W$; the difference of these values is estimated to be the load of snow on the roof, $L$. The equation generated is

$$
L=\Sigma W-\Sigma V=k \Sigma P-\Sigma V .
$$

This snow load, $L \mathrm{Nm}^{-2}$, is calculated every minute and indicated on the CRT monitor. When snowfall lasts for a long time, $L$ increases steadily. Between snow falls, natural thawing takes place and water from melted snow flows down to the storage tank from the roof. Accordingly, sometimes $L$ decreases naturally. When $L$ reaches the upper limit of snow load, $L H$, the computer switches on the heater and melting begins. The rate of melting snow is $2.0 \mathrm{~kg} \mathrm{~m}^{-2} \mathrm{~h}^{-1}$, assuming the water content of snow to be $0 \%$ and the thermal efficiency to be $100 \%$. If the density of the newly fallen snow is $0.1 \mathrm{~g} \mathrm{~cm}^{-3}$, this corresponds to a snowfall rate of $2.0 \mathrm{~cm} \mathrm{~h}^{-1}$. The melt rate determined in this manner is probably within 50$70 \%$ of the true melt rate.

As melting snow advances, $L$ decreases and eventually $L L$ is reached. Power to the heater is then cut off. Outflow of water lasts for a while after the power is off, but usually stops within an hour. The value of $L$ at this time is the remaining load.

\section{EXPERIMENTAL RESULTS}

A preliminary experiment was conducted for 8 days, from 30 December 1989 to 7 January 1990. The precipitation measured by the snowfall detector was $102 \mathrm{~kg} \mathrm{~m}^{-2}$, and the discharged water from the roof was $131 \mathrm{~kg} \mathrm{~m}^{-2}$, or 1.28 times the amount of precipitation. Therefore $k$ can be estimated to be 1.28.

The main experiment ran from 7 January to 5 February 1990. During this period, the automatic control system worked continuously. Once the system started working, the computer recorded the quantity of precipitation $P$ and the quantity of discharged water $V$ every minute. $P$ and $V$ were converted to the weight per unit area, and were summed up to the daily quantity as well as to the integrated value from the starting date of the experiment.

The precipitation on the roof, $W$, was estimated to be $(k \times \Sigma P)$, where $k=1.28$; the integrated precipitation on the roof, $\Sigma W$, was estimated to be $(k \times \Sigma P)$. Therefore, Equation (2) shows the snow load, $L$, on the roof as

$$
L=1.28 \Sigma P-\Sigma V \text {. }
$$

The upper limit of the load, $L H$, was set at $490 \mathrm{Nm}^{-2}$ $\left(50 \mathrm{~kg} \mathrm{~m}^{-2}\right)$ and the lower limit of the load, $L L$, was set at $294 \mathrm{kPa}\left(30 \mathrm{Nm}^{-2}\right)$. When $L$ reached $L H$, the electric heater was switched on automatically, and melting began. As melting proceeded and water was discharged, $L$ decreased. When $L$ reached $L L$, the electric heater was switched off and shortly thereafter the melting stopped.

Table 1. Records of melting snow on the roof during three periods

Period

I

II

III

Total

Duration of heating $(\mathrm{h})$

Quantity of water discharged $\left(\mathrm{kg} \mathrm{m}^{-2}\right)$

Heat supplied $\left(\mathrm{MJ} \mathrm{m}^{-2}\right)$

Thermal efficiency

Highest air temperature, during prior $24 \mathrm{~h}$

Lowest air temperature, during prior $24 \mathrm{~h}$

$\begin{array}{rllr}15.8 & 19.6 & 22.6 & 58.0 \\ 45.4 & 37.3 & 36.4 & 119.1 \\ 10.5 & 13.2 & 15.2 & 39.1 \\ & 94.6 \% & 80.0 \% & \\ >+10^{\circ} \mathrm{C} & +2.9^{\circ} \mathrm{C} & +0.6^{\circ} \mathrm{C} & \\ -2.2^{\circ} \mathrm{C} & -7.0^{\circ} \mathrm{C} & -3.8^{\circ} \mathrm{C} & \end{array}$

19.1

39.1 


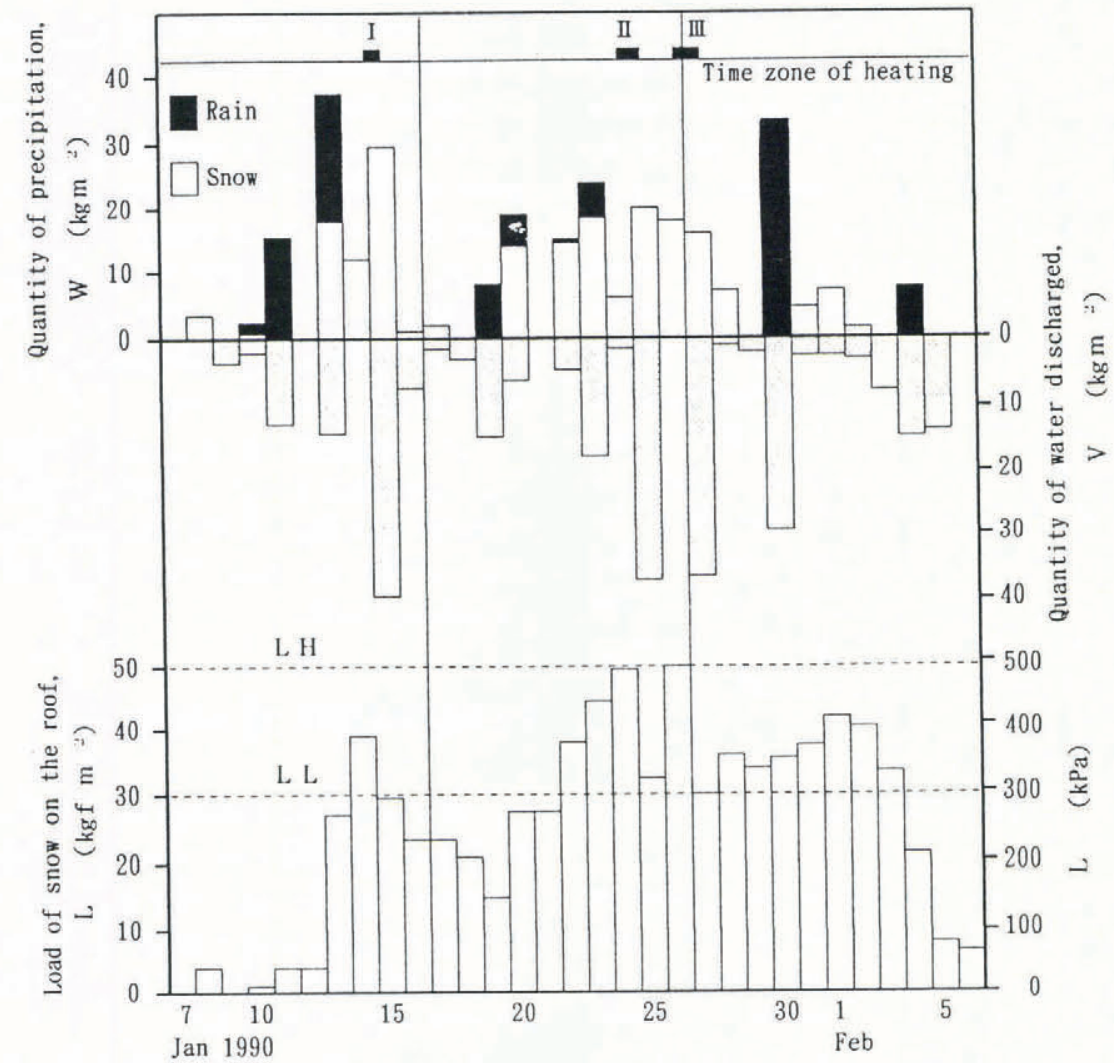

Fig. 4. Precipitation and load results showing daily quantity of snowfall and rainfall, water discharged, and roof snow load for the experimental roof.

Figure 4 presents findings during the test period. The electric heaters were energized three times (I, II and III).

So far as the data shows, it seems that $L$ has not exceeded the value of $L H$. But the snow load has not been measured directly by strain gauge or load-cell. Therefore, an accurate indication of the weight exceeding the value $L H$ is unknown.

According to the record of wind velocity during this experiment, the maximum value was $5 \mathrm{~m} \mathrm{~s}^{-1}$ and the mean value was about $2 \mathrm{~m} \mathrm{~s}^{-1}$. With such low wind speeds there would be very little error with the capture ratio and no snow drifting. The roof and the detector were placed only $1 \mathrm{~m}$ apart.

Various values measured on the three occasions when the heater was energized are shown in Table 1. The heater was on only $58 \mathrm{~h}$ during the month-long test.

On 6 February, the snow cover on the roof disappeared and the experiment ended. The amount of precipitation per unit area $(\Sigma W)$ up to this date was $288.6 \mathrm{~kg} \mathrm{~m}^{-2}$ and the quantity of water discharged per unit area $(\Sigma V)$ was $280.3 \mathrm{~kg} \mathrm{~m}^{-2}$. The ratio of the $8.3 \mathrm{~kg} \mathrm{~m}^{-2}$ difference of the latter, to the quantity of water discharged is $2.9 \%$. Independent measurements of the quantity of water discharged generated a value of $287.9 \mathrm{~kg} \mathrm{~m}^{-2}$, which is nearly equal to the gross precipitation. The differences are due to small measurement errors at the discharging unit. The thermal efficiency of the melting system cannot be calculated accurately since the water content of snow cover before and after each melting period is not known. However, if the change of the atmospheric temperature within $24 \mathrm{~h}$ prior to heating is observed, the water content of snow on the roof in the case of III in Table 1 appears to be the least. By assuming the water content to be 0 then, the thermal efficiency is $80 \%$.

\section{DISGUSSION AND GONCLUSIONS}

In this experiment, the roof snow loads are estimated from the difference between precipitation measurements and measurements of the quantity of water discharged from the roof. Roof loads are not directly measured. Since the precipitation and the quantity of water discharged only differ by about $3 \%$, calculations by these independent measurements probably approximate to the actual value. Thus, this system can be used for continuous observation of roof snow loads. The experiment also suggests that accurate and automatic control of snow melting on roofs is possible. This experiment was made on a small model roof; additional studies are needed on actual house roofs.

\section{REFERENCES}

Kimura, T. 1974. Melting of snow on roofs. Seppyo. Journal of the Japanese Society of Snow and Ice, 36(4), 1621. [In Japanese.]

Tamura, M. 1990. Snow and rain fall frequencies in Nagaoka. Seppyo. Fournal of the Japanese Society of Snow and Ice, 52(4), 251-257. [In Japanese with English summary.]

Tamura, M. In press. Continuous measurement of snowfall intensity per short time unit. CRREL Spec. Rep.

The accuracy of references in the text and in this list is the responsibility of the author, to whom queries should be addressed. 